\title{
The Relationship between the Pharmacological Effect of Amitriptyline Based on an Improved Forced-Swimming Test and Plasma Concentration in Rats
}

\author{
Natsuo OHShima, Hajime KotaKi, ${ }^{*}$ Yasufumi Sawada, and Tatsuji IgA \\ Department of Pharmacy, The University of Tokyo Hospital, Faculty of Medicine, The University of Tokyo, Hongo, \\ Bunkyo-ku, Tokyo 113, Japan. Received May 20, 1994; accepted September 5, 1994
}

\begin{abstract}
The relationship between the plasma concentration of amitriptyline (AMI) and its pharmacological effect was investigated in rats. The plasma concentration of AMI was maintained constantly from $5 \mathrm{~h}$ to $7 \mathrm{~d}$ after intraperitoneal infusion by the implantation of an osmotic minipump with an adjusted release rate of $20 \mathrm{mg} / \mathrm{kg} / \mathrm{d}$ of AMI. Neither the plasma or brain concentrations of AMI in a 24-h infusion group were significantly different as compared with those in the 7-d group. The pharmacological effect of AMI was measured by our improved forced-swimming test. When AMI (dose of 20 and $50 \mathrm{mg} / \mathrm{kg} / \mathrm{d}$ ) was infused, the pharmacological effect in both infusion groups of rats was increased significantly at each dose in comparison to that of the control rats $(p<0.05)$. With $10 \mathrm{mg} / \mathrm{kg} / \mathrm{d}$ infusion, the effect in the 7-d group increased significantly as compared with that of the control $(p<0.05)$, although the effect in the 24-h group did not change. The effect was increased in both groups with an increase of dose. When the effect was plotted to the area under the plasma concentration-time curve $(A U C)$, the effect approached a limiting value $(12 \mu \mathrm{g} / \mathrm{ml} \cdot \mathrm{h})$. Therefore, it was suggested that $12 \mu \mathrm{g} \cdot \mathrm{ml} / \mathrm{h}$ as the $A U C$ for AMI was enough to obtain a maximum AMI pharmacological effect in rats. From these results, we concluded that the $A U C$ for AMI may be a useful index to evaluate its pharmacological effect, rather than the plasma concentration.
\end{abstract}

Keywords amitriptyline; plasma level; pharmacological effect; forced swimming test

Amitriptyline (AMI), a tricyclic antidepressant, has both antidepressive and anxietic action. A delayed onset in the clinical effectiveness of AMI has been well documented. ${ }^{1,2)}$ Therefore, chronic administration of AMI is necessary in the treatment of depression. Although there have been several reports on the pharmacokinetic behavior of AMI and its clinical effect, the relationship between plasma concentration and effect was not fully elucidated. ${ }^{3,4)}$ To evaluate the quantitative relationship between the plasma concentration of AMI and its antidepressive action, it will be desirable to measure the pharmacological effect while maintaining a constant plasma concentration of AMI. In many pharmacological studies in rats, AMI was administered repeatedly once or twice a day intraperitoneally. However, it seems that the designs of these studies may be not adequate for comparison with the situation in human because the elimination half-life for this agent in rats is much shorter (approximately $90 \mathrm{~min}$ ) than that in human $\left(10-45\right.$ h). ${ }^{5}$ Recently, Kuwata et al. reported ${ }^{6)}$ that the plasma and brain concentrations of clomipramine were maintained constantly over a week by using a osmotic minipump.

Additionally the forced swimming test described by Porsolt et al. ${ }^{7)}$ has been used widely as a behavioral screening method for antidepressants. Kawashima et al. ${ }^{8)}$ evaluated the pharmacological effect of several antidepressants using this screening test, and reported that a satisfactory effect was observed by repeated intraperitoneal (i.p.) administration of imipramine and desipramine, but not by the administration of AMI or clomipramine.

In this paper, we improved the forced swimming test developed by Porsolt et al. ${ }^{7)}$ to quantatively measure the pharmacological effect of AMI, and then investigated the relationship between the plasma concentration of AMI and its pharmacological effect based on our improved forced-swimming test.

\section{MATERIALS AND METHODS}

Animals Male Wistar strain rats (Japan Laboratory Animals Co., Tokyo, Japan) weighing $160-180 \mathrm{~g}$ ( 6 weeks old) were used in all the experiments. Animals were housed in a well ventilated cage at $20-22^{\circ} \mathrm{C}$. The rats were fed with a solid feed (Oriental Yeast Co., Tokyo), and water was given ad libitum.

Chemicals and Reagents The hydrochloride salt of AMI and the hydrochloride salt of clomipramine (used as an internal standard) were kindly supplied by Banyu Pharmaceutical Co. (Tokyo, Japan) and by Ciba-Geigy, Ltd. (Takarazuka, Japan) respectively. Rat albumin and $\alpha_{1}$ acid glycoprotein were purchased from Sigma Chemical Co. (St. Louis, MO. U.S.A.). Albumin TEST Wako and auramine-O were purchased from Wako Pure Chemical Industries (Osaka, Japan) and Koddak-Wako (Osaka, Japan), respectively. All other chemicals and reagents used were commercially available and of reagent grade.

Experiments on the Stability of AMI and Maintenance of an Initial Delivery Rate from Osmotic Minipump To investigate the stability of AMI in an aqueous solution filled into the osmotic minipump (2ML1, Alza Co., Palo Alto, U.S.A.), $10 \mathrm{ml}$ of aqueous solution containing AMI $(2.5 \mathrm{mg} / \mathrm{ml})$ was incubated at $37^{\circ} \mathrm{C}$ for $7 \mathrm{~d}$. The sample $(100 \mu 1)$ was taken at 1,3 and $7 \mathrm{~d}$, and then $100 \mu$ l of the mobile phase as a bellow containing clomipramine $(25 \mu \mathrm{g} / 100 \mu \mathrm{l})$ was added to the sample. Next, an aliquot $(10 \mu)$ was injected onto a column under the highperformance liquid chromatographic (HPLC) condition described below. To investigate the maintenance of the initial delivery rate of AMI from the minipump (delivering $10 \mu \mathrm{l} / \mathrm{h}$ ), the reservoir of minipump was filled with the aqueous solution of AMI adjusted to a release rate of $25 \mu \mathrm{g} / \mathrm{h}$. Then the minipump was immersed at $37^{\circ} \mathrm{C}$ in $20 \mathrm{ml}$ of drug-free aqueous solution and $100 \mu \mathrm{l}$ samples of the solution was taken at 1,3 and $7 \mathrm{~d}$ after immersion. 
An assay of AMI in the sample was performed as described below.

i.p. Administration of AMI Using an Osmotic Minipump The reservoir of the osmotic minipump (delivering $10 \mu \mathrm{l} / \mathrm{h}$ ) was filled with the aqueous solution of AMI adjusted to release at a rate of $20 \mathrm{mg} / \mathrm{kg} / \mathrm{d}$ on the 1 st day. This was used to maintain a constant plasma concentration of AMI. The minipump was immersed in a physiological saline solution for $2 \mathrm{~h}$ at $37^{\circ} \mathrm{C}$ to stabilize the release rate of the drug solution before implantation into an abdominal cavity. Polyethylene cannulas were inserted into the femoral artery of rats under anesthesia with ether, and the minipump was then implanted into the abdominal cavity. Blood samples ( $\mathrm{ca} .1 \mathrm{ml}$ ) were collected through the artery cannula into heparinized polyethylene tubes at $15,30 \mathrm{~min}$, $1,2,3,5,7,18$ and $24 \mathrm{~h}$, and $7 \mathrm{~d}$ after implantation. In individual rats, 3 to 4 blood samples for AMI assay were obtained. Blood was centrifuged to obtain plasma at $1620 \mathrm{~g}$ for $10 \mathrm{~min}$, then the plasma was stored at $-80^{\circ} \mathrm{C}$ until analysis.

Measurement of Pharmacological Effect and Sample Collection The pharmacological effect was measured by the forced swimming test developed by Porsolt et al. ${ }^{7)}$ with minor improvement. The method of Porsolt et al. is as follows: After rats have been individually forced to swim in a cylinder filled with water at $25^{\circ} \mathrm{C}$ for $15 \mathrm{~min}$ (the $1 \mathrm{st}$ test), animals were replaced in the cylinder $24 \mathrm{~h}$ later, and the total duration of the immobility was measured during a 5 min test (the 2 nd test). However, in our preliminary experiments, we found that there was a positive correlation between the immobility time in the 1 st and the 2 nd test $(r=0.870 ; n=15)$. Therefore, the minimization of interindividual variation in the immobility time was required for a sensitive detection of the pharmacological effect of AMI. That is, in order to minimize the interindividual variance of the intrinsic immobility of rats, we evaluated the virtual time which was obtained by subtracting the total duration of immobility before drug administration from that after administration.

First, rats were individually forced to swim the inside vertical plexiglas cylinders (height $40 \mathrm{~cm}$, diameter $18 \mathrm{~cm}$ ) containing $15 \mathrm{~cm}$ of water layer maintained at $25^{\circ} \mathrm{C}$ for $15 \mathrm{~min}$, and the total duration of immobility was measured during the first $5 \mathrm{~min}\left(T_{1}\right)$. The rat was judged to be immobile whenever it remained floating passively in the water in a slightly hunched but upright position, its head just above the surface. Rats showing $T_{1}$ value under $180 \mathrm{~s}$ were discarded. Then the minipump, adjusted for release at $10,15,20,50$ and $100 \mathrm{mg} / \mathrm{kg} / \mathrm{d}$ of $\mathrm{AMI}$ on day 1 , was implanted in the abdominal cavity while the rats were under light anesthesia with ether. As a control, the osmotic minipump filled with physiological saline solution was implanted in the same manner as above. The rats were dried for $15 \mathrm{~min}$ in a heated enclosure at $30^{\circ} \mathrm{C}$ before being returned to their home cages. At $24 \mathrm{~h}$ (24-h group) and $7 \mathrm{~d}$ (7-d group) after implantation, the animals were again tested and the duration of immobility was measured during the first $5 \mathrm{~min}\left(T_{2}\right)$. The value $(\Delta T)$ when $T_{1}$ was subtracted $T_{1}$ from $T_{2}$ was used as the index of pharmacological effect $\left(\Delta T=T_{2}-T_{1}\right)$

Blood and Brain Sample Collections Rats were de- capitated immediately after the pharmacological effect was measured. Blood ( $c a .1 \mathrm{ml}$ ) was collected and then the brain was removed. The blood was centrifuged to obtain plasma at $1620 \mathrm{~g}$ for $10 \mathrm{~min}$. The brain was rinsed with ice-cold physiological saline solution blotted with filter paper and weighed. Then, the brain was homogenized with a 3-fold volume of ice-cold physiological saline solution. The plasma and homogenate samples were frozen at $-80^{\circ} \mathrm{C}$ until analysis.

Assay of AMI and Its Metabolite in Plasma and Brain Samples The plasma and brain homogenate concentrations of AMI and its active metabolite, nortriptyline, were determined by the HPLC method of Bock et al. ${ }^{9)}$ with a modification. To $0.5 \mathrm{ml}$ of plasma or $1 \mathrm{ml}$ of brain homogenate, $0.2 \mathrm{ml}$ of $4 \mathrm{M} \mathrm{NaOH}$ solution, $0.5 \mathrm{ml}$ (for plasma) or $1 \mathrm{ml}$ (for homogenate) of water, $5 \mathrm{ml}$ of $n$-heptane, $50 \mu \mathrm{l}$ of ethanol containing $100 \mu \mathrm{g} / \mathrm{ml}$ of clomipramine (the internal standard) were added. The mixture was shaken for $5 \mathrm{~min}$ and then centrifuged at $1620 \mathrm{~g}$ for $15 \mathrm{~min}$. The organic phase was transferred to a clean tube, to which was added $1 \mathrm{ml}$ of $0.1 \mathrm{M} \mathrm{HCl}$ solution. The mixture was shaken, and then centrifuged. After removal of the organic phase, $0.2 \mathrm{ml}$ of $4 \mathrm{M} \mathrm{NaOH}$ solution and $4 \mathrm{ml}$ of $n$-heptane were added to the aqueous phase. The mixture was shaken and centrifuged. The organic phase was evaporated off under a nitrogen stream. The residue was dissolved in $40 \mu \mathrm{l}$ of methanol and the aliquot $(5-20 \mu \mathrm{l})$ was injected onto an HPLC column.

HPLC conditions were as follows: apparatus, a LC-5A liquid chromatograph and SPD-5A spectrophotometer (Shimadzu, Kyoto); detection, UV detection at $240 \mathrm{~nm}$; column, Nucleosil 5C8 (Nagel, W. Germany) $25 \mathrm{~cm} \times 4.6$ $\mathrm{mm}$; mobile phase, a mixture of acetonitrile and $50 \mathrm{~mm}$ $\mathrm{KH}_{2} \mathrm{PO}_{4}$ aqueous solution $(30: 70, \mathrm{v} / \mathrm{v})$; flow rate, $1.5 \mathrm{ml} / \mathrm{min}$; column temperature, $35^{\circ} \mathrm{C}$. The lower limits of AMI and nortriptyline in plasma and brain homogenate were $10 \mathrm{ng} / \mathrm{ml}$ each.

Assay of Albumin and $\alpha_{1}$-Acid Glycoprotein (AGP) in Plasma The albumin concentration was determined by a commercially available kit (albumin Test-Wako, Wako Pure Industry). The AGP concentration was determined according to the method using a fluorophotometric probe (auramine-O) ${ }^{10)}$

Calculation of Area under the Plasma ConcentrationTime Curve ( $A U C)$ The $A U C$ for AMI from 0 to $24 \mathrm{~h}$ or from 0 to $7 \mathrm{~d}$ after i.p. infusion was calculated by the trapezoidal rule.

Statistical Analysis Statistical analysis was performed using the Student's $t$ test with $p=0.05$ as the minimal level of significance. All results are expressed as mean values \pm standard error.

\section{RESULTS}

Stability and Maintenance of the Delivery Rate of AMI The residual ratios of AMI in the aqueous solution at 1,3 and $7 \mathrm{~d}$ after incubation at $35^{\circ} \mathrm{C}$ were $101 \pm 2$, $103 \pm 2$ and $98 \pm 3 \%(n=3)$, respectively. The cumulative amounts of AMI in the aqueous solution at 1, 3 and $7 \mathrm{~d}$ from the minipump filled with the solution containing the drug were $612 \pm 6,1835 \pm 15$ and $4151 \pm 43 \mu \mathrm{g}(n=3)$, 
respectively, which corresponded to the calculated values $(600,1800$ and $4200 \mu \mathrm{g}$, respectively).

Plasma and Brain Concentration Profiles of AMI during Continuous i.p. Infusion The time course of the plasma concentration of AMI after i.p. infusion of AMI at a rate of $20 \mathrm{mg} / \mathrm{kg} / \mathrm{d}$ on the first day is shown in Fig. 1. The plasma concentration of AMI reached the plateau level $(300 \pm 20 \mathrm{ng} / \mathrm{ml})$ at $5 \mathrm{~h}$ after starting infusion and its level was maintained for $24 \mathrm{~h}$. The plasma concentration of AMI at the 7 th day was $230 \pm 28 \mathrm{ng} / \mathrm{ml}$. The decrease in this concentration of AMI on the 7th day may have been due to the increase in body weight. That is, the body weight of rats increased from $160.2 \pm 8.0 \mathrm{~g}$ on the first day to $202.3 \pm 11.8 \mathrm{~g}$ on the 7 th day.

The plasma and brain concentrations of AMI in 24-h and 7-d groups after the infusion of 10,20 and $50 \mathrm{mg} / \mathrm{kg} / \mathrm{d}$ of AMI are shown in Fig. 2. The plasma concentration of AMI in both groups increased linearly with the dosage (Fig. 2A). Similarly, the brain concentration of AMI also increased linearly with the dosage. The metabolite, nortriptyline, concentration in the plasma and brain was not detectable in all rats. The mean brain-to-plasma concentration ratio of AMI after infusion (10, 20 and $50 \mathrm{mg} / \mathrm{kg} / \mathrm{d}$ ) was within the range of $7.7-8.4$ in the $24-\mathrm{h}$

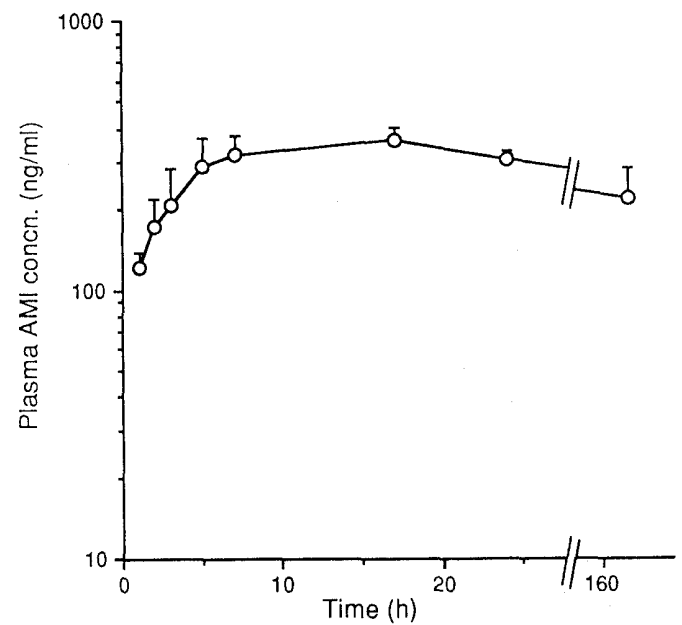

Fig. 1. Time Course of Plasma Concentration of AMI in Plasma after Intraperitoneal Infusion $(20 \mathrm{mg} / \mathrm{kg} / \mathrm{d}$ Dose of AMI) to Rats

Each point represents the mean \pm S.E. of 4 rats.

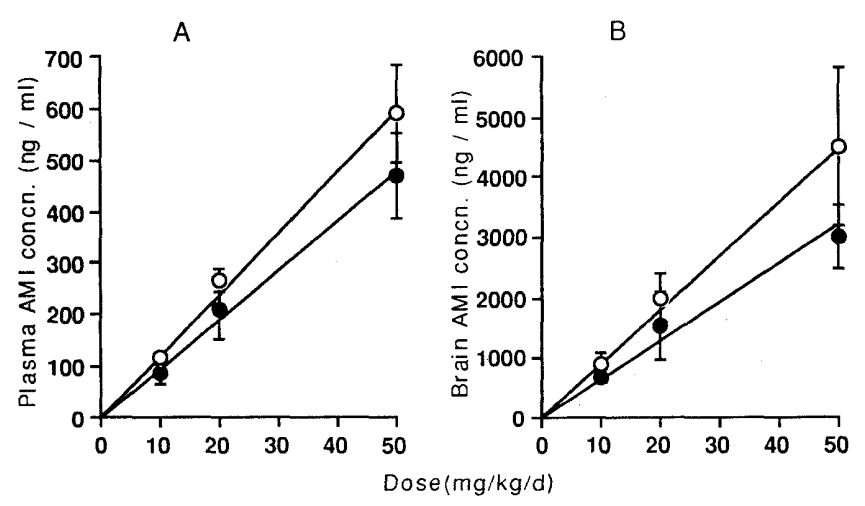

Fig. 2. Relationship between Intraperitoneal Infusion Dose and Plasma (A) or Brain (B) Concentration of AMI in 24-h and 7-d Groups

O, 24-h group; , 7-d group. Each point represents the mean \pm S.E. of 12 rats. group and $5.8-9.6$ in the $7-d$ group. The ratio was not significantly different between the two groups at each dose. However, the ratio $(5.8)$ at $50 \mathrm{mg} / \mathrm{kg} / \mathrm{d}$ in the $7-\mathrm{d}$ group tended to be smaller. The albumin concentration in plasma after infusion was almost the same between the two groups at each dose, and their albumin concentrations were not significantly different from those of the control group (Fig. 3A). The plasma concentration of AGP in the 7-d group after the infusion of $50 \mathrm{mg} / \mathrm{kg} / \mathrm{d}$ increased significantly from that of the control rats $(1.01 \pm 0.14 \mathrm{mg} / \mathrm{ml}$ versus $0.55 \pm 0.07 \mathrm{mg} / \mathrm{ml}$ ) (Fig. 3B).

Relationship between Plasma Concentration and Pharmacological Effect The immobility time $(\Delta T)$ in $24 \mathrm{~h}$ and 7-d groups at 3 different infusion doses is shown in Fig. 4. The $\Delta T$ values in the two groups after both 20 and $50 \mathrm{mg} / \mathrm{kg} / \mathrm{d}$ doses decreased significantly from that in the control group, respectively. Although the $\Delta T$ values in the 24-h group after an infusion of $10 \mathrm{mg} / \mathrm{kg} / \mathrm{d}$ was not significantly different from that in the control rats, the value in the 7-d group decreased significantly from that of the control. Further, there was a trend toward a decrease in the $\Delta T$ value with an increase in the infusion dose in the two groups.

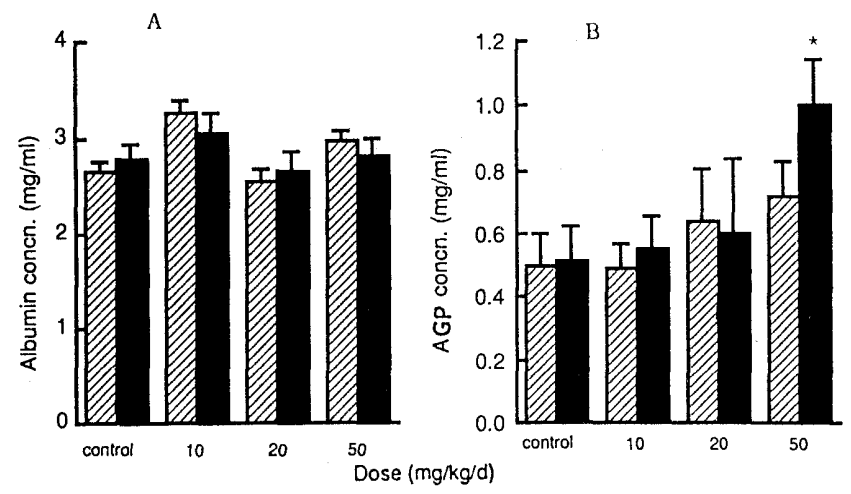

Fig. 3. Plasma Albumin (A) and AGP (B) Concentrations in 24-h and 7-d Groups after Intraperitoneal Infusions of 10,20 and $50 \mathrm{mg} / \mathrm{kg} / \mathrm{d}$ Doses of AMI

, 24-h group; 7-d group. Each point represents the mean \pm S.E. of 12 rats. *: Significantly different from the control $(p<0.05)$.

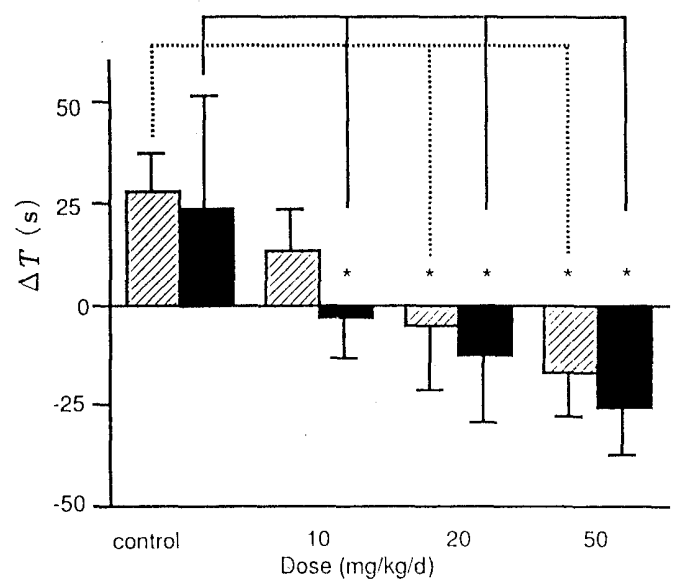

Fig. 4. Comparison of Immobility Time in 24-h and 7-d Groups after Intraperitoneal Infusion of 10,20 and $50 \mathrm{mg} / \mathrm{kg} / \mathrm{d}$ Doses of AMI

$\mathbb{Q}, 24-h$ group; $\mathbf{\square}, 7-d$ group. Each point represents the mean \pm S.E. of 12 rats. $*$ : Significantly different from the control $(p<0.05)$. 


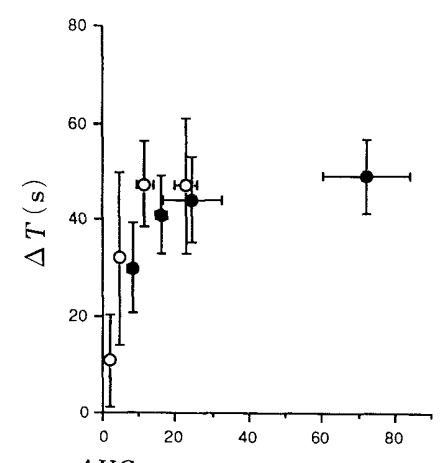

$A U C$ for AMI in plasma $(\mu \mathrm{g} \cdot \mathrm{h} / \mathrm{ml})$

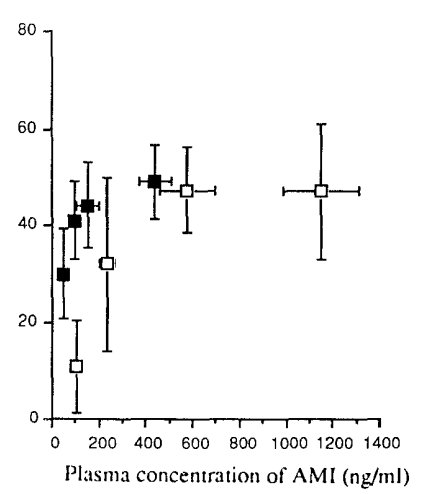

Fig. 5. Relationship between $A U C$ for AMI or the Plasma Concentration and Pharmacological Effect Measured by Forced Swimming Test after Intraperitoneal Infusion of Various Doses of AMI to Rats

$\square, O, 24-\mathrm{h}$ group (dose: $10,20,50$ and $100 \mathrm{mg} / \mathrm{kg} / \mathrm{d}$ ); $\mathbf{\square}, \mathbf{0}, 7$-d group (dose: 10 15,20 and $50 \mathrm{mg} / \mathrm{kg} / \mathrm{d}$ ). Each point represents the mean \pm S.E. of 12 rats.

The relationship between the $\Delta T$ value and plasma concentration or $A U C$ for AMI is shown in Fig. 5. The difference in the concentration dependency of the $\Delta T$ as the effect between the 24-h and 7-d groups was observed in lower concentration. This finding indicates that the pharmacological effect in the 7-d group was larger than that in the 24-h group, even though the plasma concentration of AMI was the same. However, when the $\triangle T$ value was plotted to the $A U C$ for AMI, the data points in both groups seemed to exist on a curve (Fig. 5, left panel). The $\Delta T$ value approached a limiting value (approximately $12 \mu \mathrm{g} / \mathrm{ml} \cdot \mathrm{h}$ ) as the $A U C$ increased.

\section{DISCUSSION}

Eschalier et al. ${ }^{11)}$ described that the administration of antidepressants more than twice or thrice a day would be required for pharmacological studies using small animals, since antidepressants were more rapidly eliminated from animals than from humans. However, an experimental design involving repeated administration may cause stress in animals. In addition, the conventional administration method for animal studies, such as i.p. or oral would induce large fluctuations in the plasma concentration of AMI. The osmotic minipump used in the present study was a useful tool for obtaining a steady-state condition of AMI in the body. Based on this method, the plasma level of AMI was maintained constantly from $5 \mathrm{~h}$ to $7 \mathrm{~d}$ after i.p. implantation of the minipump (Fig. 1).

The forced swimming test developed by Porsolt et al. ${ }^{7)}$ is a useful model for the screening of antidepressants in rats. In order to minimize interindividual variation, we obtained the $T_{1}$ value and $T_{2}$ value for individual rats in the 1 st test and the 2 nd test, respectively. Consequently, we can obtain the $\Delta T$ value as a useful index for quantitatively evaluating the pharmacological effect of AMI.

The mean plasma level of AMI at steady state after the infusion of a $10 \mathrm{mg} / \mathrm{kg} / \mathrm{d}$ dose was $112 \mathrm{ng} / \mathrm{ml}$. This value corresponded to the therapeutic plasma level of AMI in humans. ${ }^{2)}$ The $\Delta T$ value in the 24 -h group after a low dose infusion of AMI $(10 \mathrm{mg} / \mathrm{kg} / \mathrm{d})$ did not change, although the $\Delta T$ value was reduced markedly after a high dose infusion (20 and $50 \mathrm{mg} / \mathrm{kg} / \mathrm{d}$ ), suggesting that the onset of a pharmacological effect after acute administration of the drug is on the threshold of the plasma concentration. On the other hand, the $\Delta T$ value in the $7-\mathrm{d}$ group after the low dose infusion decreased significantly as compared with the control value. This phenomenon may be similar to the delayed onset of AMI's pharmacological effect on depression in humans. However, the cause of the delayed onset in rats may be not due to the difference in the plasma or brain concentration of AMI between the 24-h and 7-d groups after the low dose infusion, because of the similarity of the plasma or brain concentration in both groups. As shown in Fig. 5, the $\Delta T$ value in both groups was reduced with an increase in the steady-state plasma level of AMI. However, the $\Delta T$ value in the 7-d group was larger than that in the 24-h group, indicating that the plasma concentration may be not a useful index for the pharmacological effect of AMI. On the other hand, when the $\Delta T$ value was plotted to the $A U C$ s for AMI, a saturable curve was obtained and the data points in both groups seemed to exist on a curve (Fig. 5). This may suggest that the onset in effectiveness of AMI depended to both time after administration and dose. Furthermore, it is suggested that the $A U C$ of $12 \mu \mathrm{g} / \mathrm{ml} \cdot \mathrm{h}$ may be necessary to obtain the maximum effect of AMI, regardless of the dose and administration duration.

As a mechanism of the onset of effect by antidepressants, it has been well documented ${ }^{12,13)}$ that these agents involve the reduction of the number of $\beta$-adrenoceptors. Kubota reported $^{13)}$ that $\beta$-adrenoceptor density was reduced at $7 \mathrm{~d}$ after subcutaneous implantation of a minipump containing desipramine and mianserin.

A trend toward a smaller ratio of the brain to plasma concentration of AMI in the 7-d group $(50 \mathrm{mg} / \mathrm{kg} / \mathrm{d})$ may be due to an increase in AGP concentration in plasma, because it has been reported ${ }^{14,15)}$ that AMI was highly bound to plasma protein and that AGP played a dominant role in the plasma protein binding of AMI.

In conclusion, it was shown that the pharmacological effect of AMI could be measured quantitatively by the improved forced-swimming test. Although the relationship between the plasma concentration of AMI and the effect in the 24-h group after infusion of various doses of AMI was different from those in the 7-d group, the relationship between the $A U C$ and the effect was fairly consistent. Therefore, it is suggested that the $A U C$ for AMI may be a useful index for the evaluation of its pharmacological effect.

\section{REFERENCES}

1) D. S. Robinson, T. B. Cooper, C. L. Ravaris, J. O. Ives, A. Nies, D. Bartlett, K. R. Lamborn, Psychopharmacology, 63, 223 (1979).

2) D. J. Kupfer, I. Hanin, D. G. Spiker, T. Grau, P. Coble, Clin. Pharmacol. Ther., 22, 904 (1976).

3) V. E. Ziegler, B. T. Co, J. R. Taylor, P. J. Clayton, J. T. Biggs, Clin. Pharmacol. Ther., 19, 795 (1979).

4) J. E. Burck, O. Ahmed, R. P. Hullin, R. H. S. Mindham, Psychopharmacology, 94, 197 (1988).

5) A. Jorgensen, V. Hanson, Eur. J. Clin. Pharmacol., 10, 337 (1976).

6) K. Kurata, M. Kurachi, Y. Tanii, Psychopharmacology, 95, 167 (1988). 
7) R. D. Porsolt, G. Anton, N. Blavet, M. Jalfre, Eur. J. Pharmacol., 47, 379 (1978).

8) H. Kawashima, H. Araki, H. Aihara, Jpn. J. Pharmacol., 40, 199 (1986).

9) J. L. Book, E. Giller, S. Gray, P. Jatlow, Clin. Pharmacol. Ther., 31, 609 (1982)

10) Y. Sugiyama, Y. Suzuki, Y. Sawada, S. Kawasaki, T. Beppu, T. Iga, M. Hananno, Biochem. Pharmacol., 34, 821 (1985).

11) A. Eschalier, J. Fialip, O. Varoquaux, M. Makambila, H. Marty,
P. Bastide, J. Pharmacol. Exp. Ther., 245, 963 (1988).

12) G. E. Duncan, I.A. Paul, T. K. Harden, R. A. Muller, W. E. Stumpt, G. R. Breese, J. Pharmacol. Exp. Ther., 234, 402 (1985).

13) H. Kubota, J. St. Marianna University School of Medicine, 17, 465 (1989).

14) N. Ohshima, H. Kotaki, Y. Sawada, T. Iga, Drug Metab. Dispos., 22, 21 (1994).

15) E. Pike, B. Skuterud, P. Kierulf, D. Fremstad, S. M. A. Sayed, P. K. M. Lunde, Clin. Pharmacokinet., 6, 367 (1981). 